\title{
Cachexia and anorexia in cancer; a systematic review
}

\author{
Ali Darakhshandeh ${ }^{1}$, Mahnaz Momenzadeh ${ }^{2 *}$ \\ 'Department of Internal Medicine, Hematology and Oncology Section, Isfahan University of Medical Sciences, Isfahan, Iran \\ ${ }^{2}$ Department of Clinical Pharmacy and Pharmacy Practice, Faculty of Pharmacy and Pharmaceutical Sciences, Isfahan University of Medical \\ Sciences, Isfahan, Iran
}

\section{*Correspondence to Mahnaz Momenzadeh, Email: \\ Mahnazmomenzadehf@gmail. com}

Received 13 July 2020 Accepted 4 Oct. 2020 Published online 1 Nov. 2020

Keywords: Cachexia Anorexia, Cancer

\begin{abstract}
The treatment strategy for cancer cachexia is based on the cachexia stage of the cancer and its phenotypes, therefore interventions and expected outcomes vary. In order for the patient to get the most out of the treatment, it should be done based on the mechanism of intervention and the quality of life of patients should be addressed, including aspects of rehabilitation and reduction of the patient's suffering using a multidisciplinary team. Given the importance of the subject, the present study aims to investigate cachexia and anorexia in cancer. From the electronic databases, PubMed, Cochrane Library, Embase, Web of Sciences have been used to perform a systematic literature until 2020. Therefore, a software program (Endnote X8) has been utilized for managing electronic titles. Searches were performed with mesh terms. This review recommended that clinicians establish an interaction between cancer anorexia-cachexia syndrome (CACS) treatments and chronic pain treatments and choose the best treatment option.
\end{abstract}

Citation: Darakhshandeh A, Momenzadeh M. Cachexia and anorexia in cancer; a systematic review. Immunopathol Persa. $2021 ; 7(2): \mathrm{e} 20$. DOI:10.34172/ ipp.2021.20.

\section{Introduction}

Cancer anorexia-cachexia syndrome (CACS) is a multi-factorial clinical syndrome known as weight loss, tissue wasting, metabolic alterations and increased resting energy expenditure (1). The prevalence and incidence of CACS in cancer patients is estimated to be more than 50\%. Anorexia-cachexia is one of the most common symptoms in patients with advanced cancer. In some malignancies, especially non-small cell lung cancer, pancreatic cancer, and upper gastrointestinal cancers, weight loss occurs early in the diagnosis of cancer. Patients who have cancers that do not initially have cachexia (such as breast cancer, lymphoma, and colorectal cancer) may experience this syndrome in the last weeks of their lives (2). CACS is also an unfavorable prognostic factor that reduces the quality of life (3).

The quality of life of CACS individuals has been improved by various therapies, such as increase of nutritional supplements, stimulation of appetite, reduction of serum levels of several cytokines, and alleviation of insulin resistance.

However, all these interventions have limitations and there remains no definitive pharmacological therapy to address the

\begin{abstract}
Key point
Cancer anorexia-cachexia syndrome (CACS) is evaluated with decreased quality of life and curing cancer is not possible best approach to treatment. It is using a combination of dietary changes and pharmacologic therapies.
\end{abstract}

relevant components of this syndrome, thereby new effective therapies are needed (1). To improve the quality of life of CACS patients, treatment methods such as increasing dietary supplements, stimulating appetite, reducing insulin resistance and reducing the serum level of some cytokines can be used (4). It should be noted that these therapeutic interventions have limitations and no effective treatment has been approved and the need for new therapies is challenging. There is strong evidence that corticosteroids and progesterone compounds in appropriate doses improve appetite.

The mechanism of action of these factors is not well understood. Both reduce the production of inflammatory cytokines. Both drugs are well tolerated. In general, patients with a life expectancy of a few months or more perform better with megestrol acetate. Patients who have a life expectancy of a few

Copyright (C) 2021 The Author(s); Published by Nickan Research Institute. This is an open-access article distributed under the terms of the Creative Commons Attribution License (http://creativecommons.org/licenses/by/4.0), which permits unrestricted use, distribution, and reproduction in any medium, provided the original work is properly cited. 
weeks or those with a history of thrombophlebitis may receive dexamethasone because they are unlikely to suffer from the side effects of corticosteroids in the short term. Megestrol acetate increases weight, however, this increase is accompanied by an increase in fluid and fat accumulation, while the drug also has anti-anabolic effects. This drug is rarely used in practice.

Complication profiles determine which medication is best for a particular patient. There is a risk of thromboembolic events, edema, dyspnea, infertility, and increased mortality with megestrol acetate, hence this drug has not improved quality of life (5).

On the other hand, patients treated with dexamethasone have a risk of myopathy, cushingoid body, muscle wasting, infection, insulin resistance and gastric ulcer. The main effect of corticosteroids is on appetite and is prescribed for advanced patients who do not eat for 1-3 weeks. The treatment strategy for cancer cachexia is based on the cachexia stage of the cancer and its phenotypes, so interventions and expected outcomes vary.

In order for the patient to get the most out of the treatment, it should be done based on the mechanism of intervention and the quality of life of patients should be addressed, including aspects of rehabilitation and reduction of the patient's suffering using a multidisciplinary team. Accordingly, more medications and studies are needed. Given the importance of the subject, the present study aims to investigate cachexia and anorexia in cancer.

\section{Methods}

\section{Search strategy}

From the electronic databases, PubMed, Cochrane Library, Embase, Web of Science have been used to perform a systematic literature until 2020. Therefore, a software program (Endnote X8) has been utilized for managing electronic titles. Searches were performed with MESH terms;

("Cachexia”[Mesh]) AND “Anorexia"[Mesh]) AND "Neoplasms"[Mesh]) AND "Diagnosis"[Mesh]) AND "etiology" [Subheading]) AND "Hypothalamus"[Mesh]) AND "Leptin"[Mesh]) AND "Carbohydrate Metabolism"[Mesh]) AND ("Neuropeptide Y"[Mesh] OR “Receptors, Neuropeptide Y”[Mesh] )) AND “Lipid Metabolism"[Mesh]) AND “Proteins"[Mesh]) AND ("therapy" [Subheading] OR “Therapeutics"[Mesh] OR “TreatmentOutcome"[Mesh]))AND"Progesterone"[Mesh]) AND “Adrenal Cortex Hormones"[Mesh]) AND "Cannabinoids"[Mesh]) AND “Cyproheptadine"[Mesh]) AND "Amino Acids, Branched-Chain"[Mesh]) AND "AU 130" [Supplementary Concept]) AND “Ghrelin"[Mesh]) AND ( "Fatty Acids, Omega-3"[Mesh] OR "omega-3 fatty acid desaturase" [Supplementary Concept] OR "Eicosapentaenoic Acid"[Mesh] ).

Inclusion criteria; All studies except reviews, cachexia and anorexia in cancer, any treatment of cachexia and anorexia in cancer and patients with cachexia and anorexia in cancer, in English.

\section{Diagnosis}

Appetite reduction is used to diagnose anorexia. Thus, clinicians use analog visual scales and questionnaires to diagnose anorexia. These tools focus on the symptoms of food intake and the predictive of anorexia. Predictive symptoms of anorexia include early satiety, taste alterations, smell alterations, meat aversion, and nausea/vomiting $(6,7)$. While diagnosis of cachexia is controversial and challenging, it can remain years without clinical manifestations. Clinicians consider body weight to be a major indicator of nutritional status. For any patient diagnosed with cancer who loses $5 \%$ of their body weight within six months, cachexia should be suspected $(2,8)$.

\section{Pathogenesis}

The exact mechanism of CACS is currently unclear, as it is a complex phenomenon involving several biochemical and neurochemical pathways. So far, various pathways have been proven to be important in the extension of this syndrome (9).

\section{Changes in gastrointestinal system}

Abnormalities that lead to gastrointestinal system include mucositis, enteritis, dysphagia, odynophagia, and mechanical obstructions, which are seen in most cancer patients. These factors can be the result of chemotherapy and radiation therapy. All of these factors can play a role in the development of CACS (10).

\section{Hypothalamus}

The hypothalamus controls how much the body consumes under normal physiological conditions. If the hypothalamus does not respond properly to peripheral signals, which increase energy intake, the person becomes anorexic $(9,11)$.

\section{Leptin}

An important hormone produced by adipose tissue that leads to anorexia is called leptin. Under normal conditions, the body decreases leptin levels with weight loss. Low levels of this hormone lead to decreased energy intake, decrease in anorexigenic signals and increase in areas of the hypothalamus that increase appetite. The exact opposite happens when a person suffering from CACS, in which case, the leptin levels are high despite weight loss, as a result, increased leptin levels cause further protein breakdown, muscle wasting and ultimately weight loss (12-14).

\section{Carbohydrate metabolism}

In patients with CACS, large amounts of lactate are produced, which, as we know, are converted into glucose in the liver through the Cori cycle. This method led to the use of more adenosine triphosphate (ATP), thus increased 
energy expenditures and increased resting metabolic rate, leading to muscle breakdown and subsequent weight loss $(9,12,15)$

\section{Altered neuropeptide $\mathrm{Y}$ regulation}

A major component in the appetite stimulation pathway is neuropeptide $\mathrm{Y}$, which includes galanin, opioid peptide, melanin concentration hormone, orexin and agouti-related peptide $(16,17)$. Studies have shown that neuropeptide $\mathrm{Y}$ levels are reduced in mice with tumors. However, the importance of neuropeptide $\mathrm{Y}$ in cancer anorexia is currently unclear and needs further research.

\section{Dysfunctional lipid metabolism}

In CACS, cytokines inhibit lipoprotein lipase, which leads to increased lipids in the circulation and decreased fat storage $(18,19)$. On the other hand, lipid mobilizing factor (LMF) which is isolated from animal tests, can be responsible for weight loss in patients with this syndrome
$(20,21)$. Further studies however are needed in this area.

Changes in protein metabolism

A shift in the balance between protein breakdown and protein synthesis is seen in the CACS. The etiology can be attributed to the cause of proteolysis-inducing factor (PIF)(9,22-24). Studies have shown that PIF is found in the urine of patients with this syndrome and further studies in this area are important.

\section{Treatment}

One of the best and most effective treatments for cancer anorexia cachexia syndrome is to treat and cure the underlying cancer, which is often impossible and other ways must be sought. Dietary counseling and pharmacologic therapy may be effective in treating this syndrome. However, with proper management in the treatment of this syndrome, patients may experience anorexia and cachexia. Table 1 showed treatment options.

Table 1. Treatment options of CACS

\begin{tabular}{|c|c|}
\hline \multicolumn{2}{|l|}{ Treatment options } \\
\hline Dietary Counseling & $\begin{array}{l}\text { Eat in environments that bring them happiness and enjoyment. } \\
\text { Take oral supplements } \\
\text { Consume frequent small meals } \\
\text { Insure that food is aesthetically pleasing } \\
\text { Avoid extremes in taste and smell } \\
\text { Eat foods low in fat } \\
\text { Consume energy dense foods }\end{array}$ \\
\hline \multirow{5}{*}{ Progesterone } & $\begin{array}{l}\text { Key adverse side effects: thromboembolic phenomena, hyperglycemia, hypertension, adrenal suppression, and adrenal insufficiency } \\
\text { with abrupt discontinuation. }\end{array}$ \\
\hline & Two most common agents are megestrol acetate and medroxyprogesterone \\
\hline & Precise mechanism of action unknown \\
\hline & $\begin{array}{l}\text { Megestrol has been shown to have positive effects on appetite, calorie intake, and body weight (mostly through and increased fat and } \\
\text { water retention) }\end{array}$ \\
\hline & First line agents for CACS \\
\hline Corticosteroids & $\begin{array}{l}\text { Commonly used agents include prednisone, prednisolone, methylprednisolone, and dexamethasone. } \\
\text { Key adverse effects; osteoporosis, hyperglycemia, delirium, gastric ulcers, hypertension, and weakness } \\
\text { No significant impact on body weight } \\
\text { Have significant anti-nausea effects } \\
\text { Less hypothalamic pituitary axis suppression may occur with intermediate acting steroids } \\
\text { Some studies have shown positive effects on appetite and food intake } \\
\text { All glucocorticoids are equivalent in ability to stimulate appetite }\end{array}$ \\
\hline \multirow{3}{*}{ Cannabinoids } & Key adverse effects: dizziness, drowsiness, and lightheadedness \\
\hline & Dronabinol is the chemical responsible for appetite changes and body weight changes. \\
\hline & Can improve appetite and body weight slightly \\
\hline \multirow{2}{*}{ Cyproheptadine } & Improves appetite slightly, no effect on body weight. \\
\hline & Antiserotonergic and antihistamine effects \\
\hline \multirow{2}{*}{$\begin{array}{l}\text { Branched chain } \\
\text { amino acids (BCAAs) }\end{array}$} & Theoretically serve as substrates for muscle metabolism and gluconeogenesis \\
\hline & Oral BCAAs have been used to decrease severity of anorexia \\
\hline \multirow{3}{*}{ Prokinetic drugs } & Used primarily for patients with conditions such as gastric stasis and delayed gastric emptying which can lead to nausea and vomiting \\
\hline & Metoclopramide is a common agent \\
\hline & Slow release preferred over immediate release to help provide continuous stimulation \\
\hline \multirow{3}{*}{ Ghrelin } & IV ghrelin infusion have been shown to increase energy intake. \\
\hline & Key adverse effect is that they can cause increased tumor growth \\
\hline & Ghrelin stimulate appetite \\
\hline \multirow{3}{*}{ Omega-3 fatty acids } & Interferes with LMF and PIF \\
\hline & Has been shown to have positive effects on weight gain and body \\
\hline & Eicosapentaenoic acid is a common agent \\
\hline
\end{tabular}


Clinical, serum and nutritional assessment of CACS

Body weight, skeletal muscle mass, food intake recall or diary, fatigue, range of motion, quality-of-life surveys and Karnofsky Performance Scale are used for clinical diagnosis. Additionally, serum CRP (C-reactive protein), serum fibrinogen, plasma hematocrit and serum albumin are used for serum diagnosis. Furthermore, indirect calorimetry and dual X-ray absorptiometry are used for nutritional diagnosis (25-27). Table 2 shows findings of this diagnosis.

\section{Prognosis}

Cancer patients with cachexia-induced weight loss ( $\geq 5 \%$ body weight lost involuntary) experienced shorter median survival times than cancer patients without weight loss. The patients with weight loss had poorer responses to chemotherapy and experienced more treatment toxicities (28).

Health-related quality of life

A variety of health-related quality of life tools, both generic and disease specific, were used to assess the impact of CACS in primary research studies. It appears that researchers favored the use of EORTC QLQ-C30 and FACT. Nevertheless, there is no evidence that these instruments have been compared against each other in order to determine whether one is more sensitive to small changes in health-related quality of life of cancer patients suffering from CACS. As concluded in a recent systematic review, none of the existing health-related quality of life tools covers all of the domains that are affected by CACS. Improvement in health-related quality of life was reported in studies that evaluated drug therapies and integrated treatment based on pharmaconutritional support and nutritional supplements(29).

\section{Conclusion}

Since the CACS is evaluated with decreased survival and decreased quality of life and curing cancer is not possible, therefore the best approach to treatment, is important and necessary to using combination of dietary changes and pharmacologic therapies such and progesterone, corticosteroids and cannabinoids. Recommended that clinicians establish an interaction between CACS treatments and chronic pain treatments and choose the best treatment option.

\section{Authors' contribution}

$A D$ and $M M$ were the principal investigators of the study. $A D$ participated in preparing the concept and design. MM revised the manuscript and critically evaluated the intellectual contents. All authors participated in preparing the final draft of the manuscript, revised the manuscript and critically evaluated the intellectual contents. All authors have read and approved the content of the manuscript and confirmed the accuracy or integrity of any part of the work.

\section{Conflicts of interest}

The authors declare that they have no competing interests.

\section{Ethical considerations}

Ethical issues (including plagiarism, data fabrication, double publication) have been completely observed by the authors.

\section{Funding/Support}

None.

\section{References}

1. Tarricone R, Ricca G, Nyanzi-Wakholi B, Medina-Lara A. Impact of cancer anorexia-cachexia syndrome on healthrelated quality of life and resource utilisation: A systematic review. Crit Rev Oncol Hematol. 2016;99:49-62. doi: 10.1016/j.critrevonc.2015.12.008.

2. Bai Y, Hu Y, Zhao Y, Yu X, Xu J, Hua Z, Zhao Z. Anamorelin for cancer anorexia-cachexia syndrome: a systematic review and meta-analysis. Support Care Cancer. 2017;25:1651-9. doi: 10.1007/s00520-016-3560-0.

3. Fearon K, Strasser F, Anker SD, Bosaeus I, Bruera E, Fainsinger RL. Definition and classification of cancer cachexia: an international consensus. Lancet Oncol. 2011;12:489-95. doi: 10.1016/S1470-2045(10)70218-7.

4. Madeddu C, Maccio A, Mantovani G. Multitargeted treatment of cancer cachexia. Crit Rev Oncog. 2012;17:305-14. doi: 10.1615/critrevoncog.v17.i3.80.

5. Ruiz-García V, López-Briz E, Carbonell-Sanchis R, Bort-Martí S, Gonzálvez-Perales JL. Megestrol acetate for cachexia-anorexia syndrome. A systematic review. J Cachexia Sarcopenia Muscle. 2018;9:444-52. doi: 10.1002/jcsm.12292.

6. Laviano A, Meguid MM, Inui A, Muscaritoli M, Rossi-Fanelli F. Therapy insight: Cancer anorexia-cachexia syndrome--when all you can eat is yourself. Nat Clin Pract Oncol. 2005;2:158-

Table 2. Clinical, Serum and Nutritional assessment of CACS

\begin{tabular}{llllll}
\hline Clinical diagnosis & Body Weight & $\begin{array}{l}\text { Skeletal muscle } \\
\text { mass }\end{array}$ & $\begin{array}{l}\text { Food intake recall or } \\
\text { diary }\end{array}$ & $\begin{array}{l}\text { Fatique, Range } \\
\text { of motion }\end{array}$ & $\begin{array}{l}\text { Quality-of-life } \\
\text { Performance Scale }\end{array}$ \\
\hline Result & $\begin{array}{l}\text { Unintentional weight } \\
\text { loss }(>5 \% \text { during } \\
\text { preceding 6 months) }\end{array}$ & $\begin{array}{l}\text { Decreases } \\
\text { biceps, } \\
\text { quadriceps } \\
\text { muscle mass }\end{array}$ & $\begin{array}{l}\text { Anorexia and/or } \\
\text { decreased food intake }\end{array}$ & $\begin{array}{l}\text { Increased } \\
\text { Karnofsky } \\
\text { Performance Scale }\end{array}$ & $\begin{array}{l}\text { Decreased } \\
\text { scores }\end{array}$ \\
\hline Serum diagnosis & Serum CRP & Serum fibrinogen & Serum hematocrit & Serum albumin \\
\hline Result & Increased & Increased & Decreased & Decreased \\
\hline $\begin{array}{l}\text { Nutritional } \\
\text { diagnosis }\end{array}$ & Indirect calorimetry & $\begin{array}{l}\text { Dual X-ray } \\
\text { absorptiometry }\end{array}$ & \\
\hline Result & Increased in resting energy expenditure & $\begin{array}{l}\text { Decreased in lean body } \\
\text { mass }\end{array}$ & \\
\hline
\end{tabular}


65. doi: 10.1038/ncponc0112.

7. Cabeza C, Corsi O, Pérez-Cruz P. Are cannabinoids an alternative for cachexia-anorexia syndrome in patients with advanced cancer? Medwave. 2017;17:e7130. doi: 10.5867/ medwave.2017.09.7130.

8. Inui A. Cancer anorexia-cachexia syndrome: current issues in research and management. CA Cancer J Clin. 2002;52:72-91. doi: 10.3322/canjclin.52.2.72.

9. Zhang J, Deng Y, Khoo BL. Fasting to enhance Cancer treatment in models: the next steps. J Biomed Sci 2020;27:58. doi: 10.1186/s12929-020-00651-0

10. van Norren K, Dwarkasing JT, Witkamp RF. The role of hypothalamic inflammation, the hypothalamic-pituitaryadrenal axis and serotonin in the cancer anorexia-cachexia syndrome. Curr Opin Clin Nutr Metab Care. 2017;20:396401. doi: 10.1097/MCO.0000000000000401.

11. Balcázar-Hernández L, Vargas-Ortega G, Valverde-García Y, Mendoza-Zubieta V, González-Virla B. Anorexia-cachexia syndrome-like hypothalamic neuroendocrine dysfunction in a patient with a papillary craniopharyngioma. Endocrinol Diabetes Metab Case Rep. 2017;2017:17-0018. doi:10.1530/ EDM-17-0018

12. Graf SA, Garcia JM. Anamorelin hydrochloride in the treatment of cancer anorexia-cachexia syndrome: design, development, and potential place in therapy. Drug Des Devel Ther. 2017:11:2325-31. doi: 10.2147/DDDT.S110131.

13. De Breucker S, Luce S, Njemini R, Bautmans I, Decoster L, Mets T, Pepersack T. Analysis of inflammatory markers and hormones in old cancer patients: A descriptive study. Exp Gerontol. 2020;130:110787. doi: 10.1016/j.exger.2019.110787.

14. Ohnuma T, Ali MA, Adigun R. Cancer, Anorexia and Cachexia. [Updated 2020 Aug 10]. In: StatPearls [Internet]. Treasure Island (FL): StatPearls Publishing; 2020 Jan-. Available from: https://www.ncbi.nlm.nih.gov/books/NBK430977/.

15. Shyh-Chang N. Metabolic Changes During Cancer Cachexia Pathogenesis. Adv Exp Med Biol. 2017;1026:233-249. doi: 10.1007/978-981-10-6020-5_11.

16. Tatemoto K. Neuropeptide Y: History and Overview. In: Michel MC, eds. Neuropeptide $Y$ and Related Peptides. Handbook of Experimental Pharmacology. vol 162. Berlin, Heidelberg: Springer; 2004. doi:10.1007/978-3-642-18764-3_1

17. Kawai K, Nakashima M, Kojima M, Yamashita S, Takakura $S$, Shimizu $M$, et al. Ghrelin activation and neuropeptide $Y$ elevation in response to medium chain triglyceride administration in anorexia nervosa patients. Clin Nutr ESPEN. 2017;17:100-104. doi: 10.1016/j.clnesp.2016.10.001.

18. Salazar-Tortosa DF, Pascual-Gamarra JM, Labayen I, Rupérez Al, Censi L, Béghin L, et al. Association between lipoprotein lipase gene polymorphisms and cardiovascular disease risk factors in European adolescents: The Healthy Lifestyle in Europe by Nutrition in Adolescence study. Pediatr Diabetes. 2020;21:747-57. doi: 10.1111/pedi.13035.

19. Mead JR, Irvine SA, Ramji DP. Lipoprotein lipase: structure, function, regulation, and role in disease. J Mol Med (Berl). 2002;80:753-69. doi: 10.1007/s00109-002-0384-9.

20. Sanders PM, Tisdale MJ. Role of lipid-mobilising factor (LMF) in protecting tumour cells from oxidative damage. $\mathrm{Br} J$ Cancer. 2004;90:1274-8. doi: 10.1038/sj.bjc.6601669.

21. Blum D, Omlin A, Baracos VE, Solheim TS, Tan BH, Stone P, et al. Cancer cachexia: a systematic literature review of items and domains associated with involuntary weight loss in cancer. Crit Rev Oncol Hematol. 2011;80:114-44. doi: 10.1016/j. critrevonc.2010.10.004.

22. Navarro I Batista K, Schraner M, Riediger T. Brainstem prolactinreleasing peptide contributes to cancer anorexia-cachexia syndrome in rats. Neuropharmacology. 2020;180:108289. doi: 10.1016/j.neuropharm.2020.108289.

23. van der Meij BS, De Groot LM, Deutz NEP, Engelen MPKJ. Effects of acute oral feeding on protein metabolism and muscle protein synthesis in individuals with cancer. Nutrition. 2019;67-68:110531. doi: 10.1016/j.nut.2019.06.012.

24. Argilés JM, López-Soriano FJ, Busquets S. Mediators of cachexia in cancer patients. Nutrition. 2019;66:11-15. doi: 10.1016/j.nut.2019.03.012

25. Hilal Z, Rezniczek GA, Klenke R, Dogan A, Tempfer CB. Nutritional status, cachexia, and anorexia in women with peritoneal metastasis and intraperitoneal chemotherapy: a longitudinal analysis. J Gynecol Oncol. 2017;28:e80. doi: 10.3802/jgo.2017.28.e80.

26. Nordhausen K, Solass W, Demtroeder C, Tempfer CB, Reymond M. Cachexia-anorexia syndrome in patients with peritoneal metastasis: an observational study. Pleura Peritoneum. 2016;1:57-63. doi: 10.1515/pp-2016-0003.

27. de Las Peñas R, Majem M, Perez-Altozano J, Virizuela JA, Cancer E, Diz P, et al. SEOM clinical guidelines on nutrition in cancer patients (2018). Clin Transl Oncol. 2019;21:87-93. doi: 10.1007/s12094-018-02009-3.

28. Couch M, Lai V, Cannon T, Guttridge D, Zanation A, George J, Hayes DN, Zeisel S, Shores C. Cancer cachexia syndrome in head and neck cancer patients: part I. Diagnosis, impact on quality of life and survival, and treatment. Head Neck. 2007;29:401-11. doi: 10.1002/hed.20447.

29. Mantovani G. Randomised phase III clinical trial of 5 different arms of treatment on 332 patients with cancer cachexia. Eur Rev Med Pharmacol Sci. 2010;14:292-301. 